\title{
Mind-Body Medicine: State of the Science, Implications for Practice
}

\author{
John A. Astin, PhD, Shauna L. Shapiro, PhD, David M. Eisenberg, MD, and \\ Kelly L. Forys, $M A$
}

Background: Although emerging evidence during the past several decades suggests that psychosocial factors can directly influence both physiologic function and health outcomes, medicine had failed to move beyond the biomedical model, in part because of lack of exposure to the evidence base supporting the biopsychosocial model. The literature was reviewed to examine the efficacy of representative psychosocial-mind-body interventions, including relaxation, (cognitive) behavioral therapies, meditation, imagery, biofeedback, and hypnosis for several common clinical conditions.

Methods: An electronic search was undertaken of the MEDLINE, PsycLIT, and the Cochrane Library databases and a manual search of the reference sections of relevant articles for related clinical trials and reviews of the literature. Studies examining mind-body interventions for psychological disorders were excluded. Owing to space limitations, studies examining more body-based therapies, such as yoga and tai chi chuan, were also not included. Data were extracted from relevant systematic reviews, metaanalyses, and randomized controlled trials.

Results: Drawing principally from systematic reviews and meta-analyses, there is considerable evidence of efficacy for several mind-body therapies in the treatment of coronary artery disease (eg, cardiac rehabilitation), headaches, insomnia, incontinence, chronic low back pain, disease and treatmentrelated symptoms of cancer, and improving postsurgical outcomes. We found moderate evidence of efficacy for mind-body therapies in the areas of hypertension and arthritis. Additional research is required to clarify the relative efficacy of different mind-body therapies, factors (such as specific patient characteristics) that might predict more or less successful outcomes, and mechanisms of action. Research is also necessary to examine the cost offsets associated with mind-body therapies.

Conclusions: There is now considerable evidence that an array of mind-body therapies can be used as effective adjuncts to conventional medical treatment for a number of common clinical conditions. (J Am Board Fam Pract 2003;16:131-47.)

Evidence emerging within the past several decades suggests that psychosocial factors from emotional states, such as depression, behavioral dispositions, such as hostility, and psychosocial stress can directly influence both physiologic function and health outcomes. ${ }^{1-4}$ Evidence from several converging lines of research, however, also suggests that despite seemingly widespread

Submitted, revised 16 May 2002

From the California Pacific Medical Center (JAA), San Francisco, and the Veteran's Administration (SLS), Palo Alto, Calif; the Harvard Medical School (DME), Cambridge, Mass; and the University of Maryland, Baltimore County (KLF). Address reprint requests to John A. Astin, PhD, California Pacific Medical Center, 2300 California St., Room 207, San Francisco, CA 94115.

This manuscript was completed while the first author was a faculty member in the Complementary Medicine Program at the University of Maryland School of Medicine. acknowledgment of and support for the importance of the biopsychosocial model,,$^{5-7}$ psychosocial factors continue to be overlooked or missed in many clinical encounters ${ }^{8-12}$ and are frequently underemphasized in medical education. ${ }^{13-15}$ Whereas the reasons underlying the failure of medicine to move beyond the biomedical model are no doubt complex (eg, overloaded curriculum, inadequate economic incentives), lack of exposure to the evidence base supporting the biopsychosocial model might be one such factor. Furthermore, while studies have shown that evidence of the effectiveness of a given therapy is frequently insufficient to change clinical practice, ${ }^{16}$ the generation, synthesis, and communication of research findings continue to be central tasks for evidence-based medicine. 


\begin{tabular}{lrr}
\hline & & Use by the \\
Modality & Description & Public ${ }^{17}(\%)$ \\
\hline
\end{tabular}

Relaxation techniques Relaxation techniques, broadly defined, include those practices whose primary stated goal is elicitation of a psychophysiological state of relaxation or hypoarousal. In certain practices, the goal might be to reduce muscular tension (as in progressive muscle relaxation in which muscles are alternatively tensed and relaxed). In other cases, the primary goal is to achieve a hypometabolic state of reduced sympathetic arousal. The most prominent example of the latter is Benson's relaxation response ${ }^{18,19}$

Meditation Meditation has been defined as the "intentional self-regulation of attention," a systematic mental focus on particular aspects of inner or outer experience. ${ }^{20-23}$ Unlike many approaches in behavioral medicine (eg, biofeedback, relaxation strategies), most meditation practices were developed within a religious or spiritual context and held as their ultimate goal some type of spiritual growth, personal transformation, or transcendental experience. It has been argued that as a health care intervention, meditation can be taught and used effectively regardless of a patient's cultural or religious background. ${ }^{24}$ The two most extensively researched forms are transcendental meditation, ${ }^{25}$ in which practitioners repeat a silent word or phrase (a mantra) with the goal of quieting (and ultimately transcending) the ordinary stream of internal mental dialogue, and mindfulness meditation, ${ }^{26}$ in which practitioners simply observe or attend to (without judgment) thoughts, emotions, sensations, perceptions, etc, as they arise moment by moment in the field of awareness

Guided imagery Guided imagery involves the generation (either by oneself or guided by a practitioner) of different mental images. Using the capacities of visualization and imagination, individuals evoke images, usually either sensory or affective. These images are typically visualized with the goal of evoking a psychophysiological state of relaxation or with some specific outcome in mind (eg, visualizing one's immune system attacking cancer cells, imagining oneself feeling healthy and well, exploring subconscious themes, etc)

Hypnosis

Hypnosis has been defined as "a natural state of aroused, attentive focal concentration coupled with a relative suspension of peripheral awareness." 27 Primary components of the hypnotic trance experience include (1) absorption, or the intense involvement of a central object of concentration; (2) dissociation, in which experiences that would ordinarily be experienced consciously occur outside of normal conscious awareness, in part owing to the intense absorption; and, (3) suggestibility, in which persons are more likely to accept outside input (ie, instructions, guidance) without cognitive censor or criticism $^{27}$

Biofeedback

Developed in the 1960s, biofeedback involves the use of devices that amplify physiological processes (eg, blood pressure, muscle activity) that are ordinarily difficult to perceive without some type of amplification. Participants are typically guided through relaxation and imagery exercises and instructed to alter their physiological processes using as a guide the provided biofeedback (typically visual or auditory). Examples of prominent forms of this therapy are electromyographic biofeedback, in which patients with a condition, such as tension headaches, are provided with feedback regarding the degree of tension in the frontalis muscle, or temperature biofeedback, in which patients with migraine headache disorder are instructed to warm their hands using as their feedback cue sounds or tones indicating temperature changes in this region of the body

Cognitive behavioral

Among more traditional psychological interventions, one of the more prominent MBTs is cognitive-behavioral therapy. It emphasizes the role of cognitive processes in shaping affective experience and argues that problematic emotions, such as anger, depression, and anxiety, result from irrational or faulty thinking. ${ }^{28,29}$ Behavior therapy (as distinguished from cognitive behavior approaches) tends to emphasize the use of environmental reinforcements (eg, not rewarding certain behaviors) to change or elicit certain behavioral changes.

Psychoeducational These approaches typically combine certain psychological strategies (eg, cognitive approaches behavioral coping skills training, relaxation, meditation, and imagery for stress reduction) with patient education (ie, teaching patients about their disease, appropriate treatments, self-care behaviors, and communicating with health care providers). A prototype is the Arthritis Self-Management Program developed by Lorig and colleagues $^{30}$

N/A = not available.

Note: In describing MBTs, researchers have used a number of broad, interrelated terms, including "behavioral," "psychosocial," "psychoeducational," and so on. Such variations in terminology can reflect differing approaches and emphases. Often, however, the terms simply reflect the particular theoretical orientations of the investigators (eg, those working in the complementary and alternative medicine field might refer to meditation as a mind-body therapy, whereas researchers within behavioral medicine might refer to it as a behavioral intervention). For simplicity of presentation, we have tried to use the broader term mind-body therapies throughout the article to refer collectively to these different approaches. 
The purpose, therefore, of the present review is to provide a general overview of the state of the science regarding the relative efficacy of an array of psychosocial-mind-body interventions. This article reviews the efficacy of mind-body therapies (MBTs) in the treatment of health-related problems other than mental illness or psychological difficulties. The National Institutes of Health (NIH) define MBTs as "interventions that use a variety of techniques designed to facilitate the mind's capacity to affect bodily function and symptoms." As summarized in Table 1, the prominent MBTs we examine include relaxation, meditation, imagery, hypnosis, and biofeedback.

Owing to space constraints, we have focused the review on several specific clinical areas. These areas were selected primarily because of their more extensive investigation in terms of MBTs. We do not address additional body-based approaches, such as yoga and tai chi chuan, nor do we address the research examining spiritual healing practices, such as prayer and distant healing. ${ }^{31}$ Finally, we do not review the literature of what might be termed body-mind medicine, eg, the use of exercise and massage to influence psychological function.

\section{Methods}

An electronic search of the MEDLINE, PsycLIT, and the Cochrane Library databases and a manual search of the reference sections of relevant articles was conducted. Search terms included specific MBTs (eg, relaxation therapy, biofeedback), more general terms such as "stress management," "cognitive-behavioral therapy," and the combination of these with specific health-related conditions (eg, "biofeedback and pain"). To further delimit the scope of our search, we selected systematic reviews of MBTs. When these reviews did not exist, we examined the available literature, focusing on randomized trials.

Although in theory systematic reviews reduce bias by objectively and systematically sorting out and then synthesizing results from available studies, such reviews are still prone to bias. ${ }^{32} \mathrm{We}$ therefore examined the methodological quality of the metaanalyses as an aid to assessing the validity of their conclusions. We used the instrument developed by Oxman and Guyatt ${ }^{33}$ to assess quality. This scale contains nine items and rates reviews on a scale from 1 to 7 (higher scores reflecting better quality).

\section{Results}

\section{Description of Mind-Body Therapies}

While we have characterized the various MBTs as somewhat discrete categories, there is, in fact, considerable crossover between them, eg, imagery is often included as part of meditation and relaxation; biofeedback often uses imagery and relaxation techniques. In addition, studies examining the health benefits of MBTs often combine modalities. For example, one frequently finds in the literature references to psychosocial interventions or stress management techniques that can include relaxation and biofeedback, as well as a cognitive-behavioral counseling component.

In Table 1, we have briefly described the more prominent MBTs.

\section{Quality of Reviews}

Data from 28 systematic reviews are summarized in Table 2. There was a mean quality rating of 4.5 (of 7.0). ${ }^{33}$ Eight reviews (29\%) were judged to have major methodological flaws (scoring 3 or less). Fifty percent mentioned publication bias as a potential issue, and $18 \%$ assessed whether it was present (eg, funnel plot). Fifty-seven percent tested for heterogeneity, whereas 54\% conducted sensitivity-subgroup analyses. There was a trend toward more recent reviews scoring higher on quality $(P=.06)$ and higher quality reviews being less likely to conclude that the treatment was effective.

Overall, the quality of reviews compared favorably with other areas of medicine. For example, among reviews in asthma ${ }^{63}$ and analgesia, ${ }^{64} 80 \%$ and $41 \%$, respectively, were judged to have major methodological flaws based on the Oxman-Guyatt scale.

Of particular concern in meta-analyses is the issue of publication bias. Sutton et $\mathrm{al}^{65}$ in their analysis of 48 systematic reviews, found that 54\% showed some evidence of publication bias. Additionally, while only in four cases did adjustment for publication bias change the statistical significance of the effect sizes, the failure to assess and control for publication bias could potentially invalidate the results of some meta-analyses. In our review of the five meta-analyses that assessed whether publication bias was present, none found any evidence for it. Whereas it is unclear the extent to which publication bias might have influenced the results and conclusions of the other reviews we examined, Sut- 


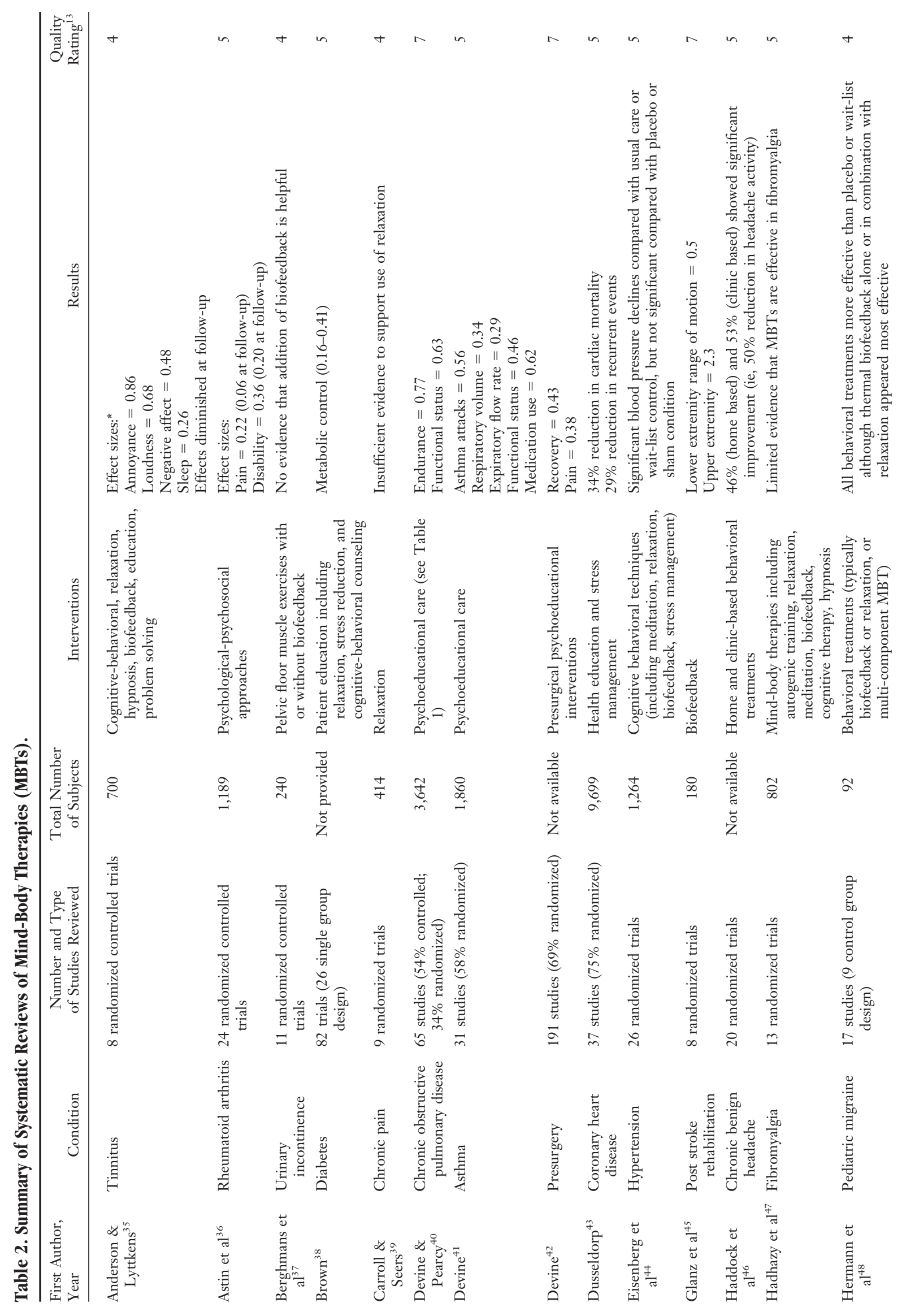

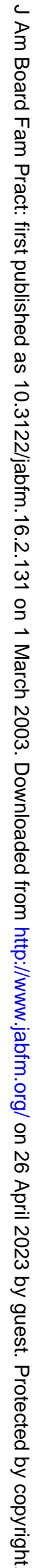



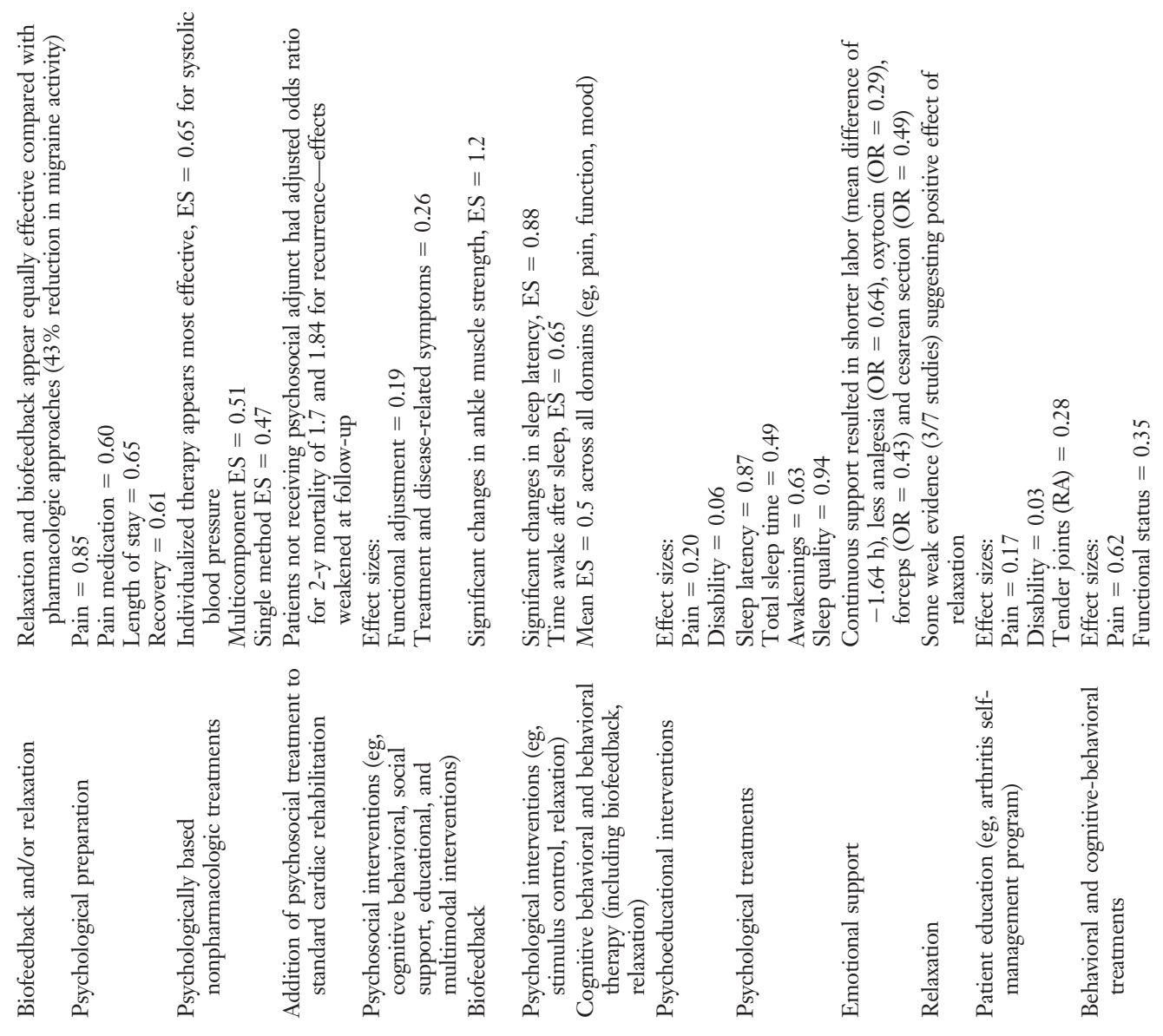

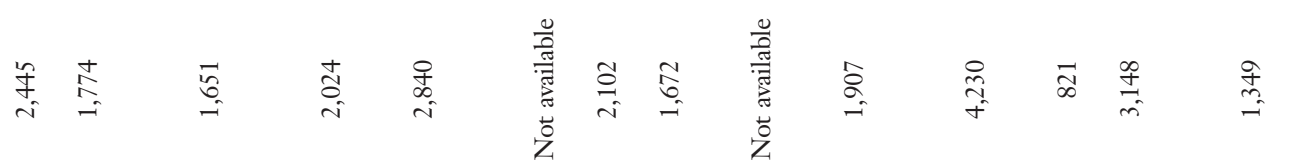
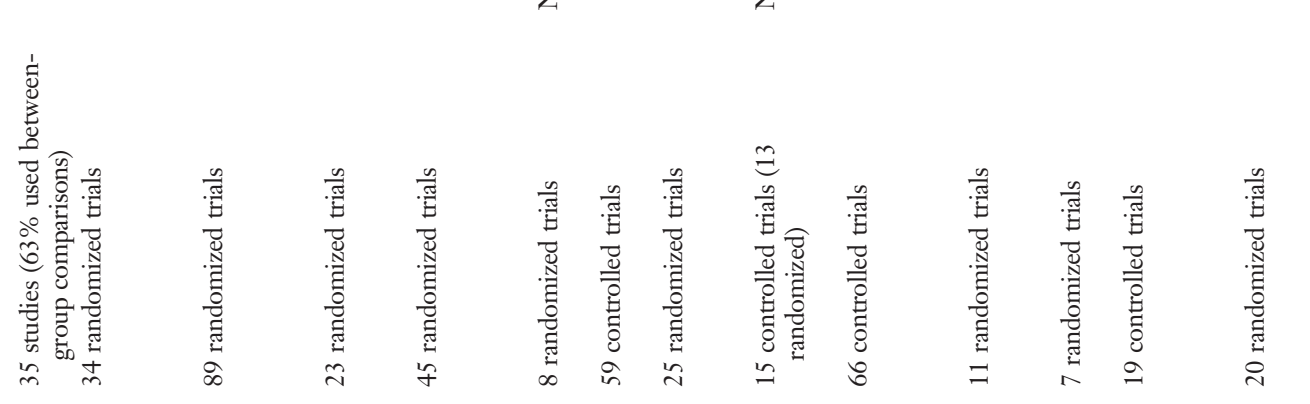

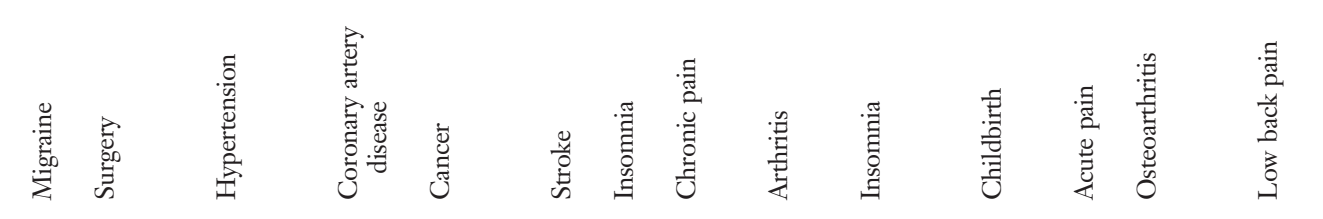

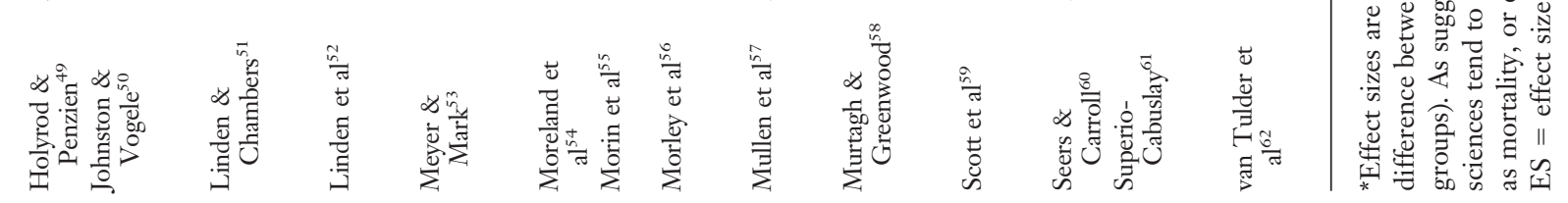


ton et $\mathrm{al}^{65}$ suggest that this number is probably fairly low (approximately 8\% based on their analysis).

To summarize, most (71\%) of the mind-body meta-analyses we examined were deemed to have either minimal or relatively minor methodological flaws, and their quality was comparable to, if not slightly better than, reviews in other areas of medicine. We therefore feel relatively confident that our overall conclusions and recommendations (which are based to a large extent on these metaanalyses) are defensible based on the current literature. That being said, because a number of reviews did contain major flaws, we suggest that future systematic reviews in the mind-body area attempt to incorporate reporting guidelines such as those discussed in the QUOROM statement. ${ }^{32}$

In addition, it is important to note that the ultimate validity of any findings derived from a systematic review must obviously be evaluated in the context of the quality of the trials themselves. Among the sample of reviews we rated, $61 \%$ included only randomized controlled trials. In those reviews in which nonrandomized trials were included, in no instance were significant differences observed when the outcomes in randomized (ie, higher quality) trials were compared with those in nonrandomized trials. In six reviews, ${ }^{38,48,49,55,58,61}$ it was not possible to determine whether trials referred to as controlled were randomized or not.

Finally, we note that a serious limitation in most mind-body studies reviewed is the absence of any placebo or sham control condition, because practitioners cannot typically be blinded to the treatment, and it is often not possible to blind patients to group assignment.

\section{Pain-Related Disorders}

\section{Arthritis}

Studies have examined the efficacy of multimodal MBTs in the treatment of osteoarthritis, rheumatoid arthritis, and fibromyalgia. These treatments typically include some combination of relaxation, biofeedback therapy, cognitive strategies (eg, for coping with pain), and education.

Narrative reviews suggest that the Arthritis SelfManagement Program (ASMP) ${ }^{30}$ might be a particularly effective adjunct in the management of arthritis. ${ }^{66}$ This community-based program consists of education, cognitive restructuring, relaxation, and physical activity to reduce pain and dis- tress and facilitate problem solving. An analysis of 501 patients (68\% osteoarthritis, $15 \%$ rheumatoid arthritis, and $17 \%$ other forms of arthritis) found that reductions in pain were maintained 4 years after the intervention, and physician visits were reduced by $40 \% .^{67}$

A 1996 meta-analysis ${ }^{61}$ compared effect sizes of psychoeducational interventions, including the ASMP, with those found in randomized trials of nonsteroidal anti-inflammatory drugs (NSAIDs). Overall, effect sizes appeared quite small for these MBTs ( 0.17 for pain, 0.03 for functional disability, 0.34 for tender joint count in rheumatoid arthritis). The authors note, however, that because most patients in these trials were already on NSAIDs, the relatively small effect sizes probably represent the additional benefit in addition to medication and might therefore be clinically relevant. There have been no randomized trials that directly compare MBTs with pharmacologic therapy.

A recent meta-analysis ${ }^{36}$ of 25 randomized trials of MBT found small but statistically significant effect sizes for pain (0.22), disability (0.36), and depression (0.17) in patients with rheumatoid arthritis. At follow-up (averaging 8.5 months), effects remained significant for all outcomes except pain, whereas effects for tender joints became significant (effect size $=0.35)$.

Findings regarding the efficacy of MBTs in fibromyalgia are equivocal. A Cochrane review of 13 controlled trials (most of which were of poor methodologic quality) found limited evidence that MBTs are more effective than waiting-list or usualcare controls and inconclusive evidence that these therapies are more effective than physiotherapy or education-attention controls. ${ }^{47}$

\section{Pain Management}

Findings regarding the efficacy of relaxation therapy alone (eg, progressive muscle relaxation) for chronic and acute pain are inconclusive. Although a 1996 NIH consensus panel stated that there was "strong" evidence that relaxation techniques were effective in the treatment of chronic pain, ${ }^{68}$ a systematic review of nine randomized trials ${ }^{39}$ found positive treatment effects in only three studies and concluded that there is insufficient evidence for the use of relaxation alone in the treatment of chronic pain. A systematic review of randomized controlled trials examining relaxation for acute pain management ${ }^{60}$ similarly concluded that though there was 
"some weak evidence" to support the use of these therapies, the data were inconclusive, in part owing to methodological limitations.

\section{Low Back Pain}

A Cochrane review examined the efficacy of MBTs in chronic low back pain. ${ }^{62}$ Twenty randomized trials were found. Interventions were categorized as operant (using reinforcement to modify behavior), cognitive (modification of cognitive responses to pain), or respondent (modification of the physiologic response system, eg, progressive muscle relaxation). Although overall, only $25 \%$ of the studies received high methodological quality ratings, the authors concluded that there was strong evidence (defined as generally consistent findings in multiple high-quality randomized controlled trials) that MBTs, when compared with wait-list controls or usual medical care, have a moderate positive effect on pain intensity (effect size $=0.62 ; 95 \%$ confidence interval [CI], 0.25-0.98) and small effects on functional status (effect size $=0.35 ; 95 \% \mathrm{CI}$, $-0.04-0.74$ ) and behavioral outcomes (effect size $=0.40 ; 95 \%$ CI, $0.10-0.70)$. Results did not shed light on the relative efficacy of the different MBTs.

\section{Headache}

A 1990 meta-analysis compared the efficacy of relaxation and biofeedback (34 trials) with drug therapy (25 trials) in recurrent migraine headache. ${ }^{49}$ Both approaches yielded similar results $-43 \%$ reduction in headache activity in the average patient compared with $14 \%$ reduction with placebo medication and no reduction in unmedicated subjects. A more recent narrative review concluded that a combination of relaxation training and thermal biofeedback is the preferred behavioral treatment for recurrent migraine disorder. ${ }^{69}$

A 1997 meta-analysis ${ }^{46}$ suggests that both home and clinic-based MBTs are more effective than waiting-list or usual-care controls in the treatment of chronic benign headache (effect size $=0.51$ and 0.52 , respectively, across all headache types and outcomes). Recent evidence indicates that stressmanagement training is as effective as tricyclic antidepressants in the management of chronic tension-type headache, suggesting that combining these two therapeutic approaches might be more effective than using either one alone. ${ }^{70}$

\section{Cancer}

Evidence from multiple studies in heterogeneous groups of cancer patients ${ }^{71}$ suggests that various MBTs can improve mood, quality of life, and coping, ${ }^{72-76}$ as well as ameliorate disease and treatmentrelated symptoms, such as chemotherapy-induced nausea and vomiting, ${ }^{77-80}$ physical pain, ${ }^{81-83}$ and functioning. ${ }^{84}$

Consistent with Devine and Westlake's 1995 meta-analysis of 80 controlled trials, ${ }^{71}$ Meyer and Mark's review of 45 randomized trials examining psychoeducational interventions for adult cancer patients ${ }^{53}$ found small but statistically significant effect sizes for treatment and disease-related symptoms (eg, pain, nausea) of 0.26 (95\% CI, $0.16-0.37$ ), functional adjustment (effect size $=$ 0.19; 95\% CI, 0.06-0.32), and emotional adjustment (effect size $=0.24 ; 95 \%$ CI, 0.17-0.32). A more recent narrative review of 54 studies examined the efficacy of an array of behavioral interventions, including contingency management, relaxation, imagery, and hypnosis, in managing treatment-related side effects in cancer patients. ${ }^{85}$ The authors concluded that such interventions were effective in reducing anticipatory nausea and vomiting and treating acute pain associated with diagnostic and treatment procedures. The evidence for chronic pain and nausea and vomiting after chemotherapy were deemed less strong.

Whereas studies suggest that MBTs can alter various immune parameters in cancer patients, ${ }^{86-88}$ it is unclear what the potential clinical importance of these changes might be in terms of disease progression. Two randomized controlled trials that attempted to correlate changes in immunologic parameters with effects on disease progression and survival failed to do so. ${ }^{89-90}$

The debate regarding whether MBTs can influence survival among cancer patients remains unresolved. Three randomized trials have shown a significant survival effect. ${ }^{90-92}$ In the most well publicized of these trials, ${ }^{91}$ women with metastatic breast cancer randomized to a 1-year weekly support and hypnosis group evidenced significant differences in survival rates at 10 -year follow-up. Despite these positive findings, results from four other randomized trials ${ }^{93-96}$ have failed to show a survival effect of these interventions. 


\section{Incontinence Disorders}

There is strong evidence that biofeedback-assisted muscle re-training is effective in the treatment of incontinence disorders, as reflected in the 1996 clinical practice guidelines from the Agency for Health Care Policy and Research that recommend behavioral treatments as a first-line treatment in urinary incontinence. ${ }^{97}$ A 1998 systematic review ${ }^{37}$ concluded that biofeedback did not add significantly to pelvic floor exercises in treating urinary incontinence in women. A meta-analytic review of five of these same trials, ${ }^{98}$ however, concluded that biofeedback-assisted pelvic floor exercises were, in fact, more effective than pelvic floor exercises alone $(\mathrm{OR}=2.1 ; 95 \%$ CI 0.99-4.4). Several recent studies ${ }^{99-101}$ provide further evidence for the efficacy of biofeedback in treating urinary incontinence. Of particular note, the randomized trial by Burgio et $\mathrm{al}^{100}$ showed that biofeedback-assisted behavioral treatment was more effective than drug therapy in reducing incontinence episodes in elderly women.

Research also suggests that biofeedback is a potentially effective treatment for patients with passive and urge fecal incontinence ${ }^{102,103}$ and impaired fecal continence after obstetric trauma, ${ }^{104}$ and constipation. ${ }^{105,106}$

\section{Cardiovascular Disease and Hypertension}

Human and animal studies show that psychological factors (eg, depression, hostility, and stress) can play a substantive role in the development and progression of cardiovascular disease. ${ }^{1}$ In the most recent review examining the role of psychological factors in coronary artery disease, the authors concluded: "A confluence of pathophysiological and epidemiologic studies establish that both acute and chronic forms of psychosocial stress contribute to the pathogenesis of coronary atherosclerosis. These data establish an imperative for enhancing behavioral interventions among CAD-prone individuals."

There is evidence that MBTs can be effective in the treatment of coronary artery disease. A 1996 meta-analysis of 23 randomized trials ${ }^{52}$ found that the addition of psychosocial treatments (eg, relaxation, group and individual psychotherapy, type A behavior modification, stress-management) to standard cardiac rehabilitation resulted in a $41 \%$ reduction in all-cause mortality and a $46 \%$ reduction in nonfatal cardiac recurrences at a 2-year follow-up. When patients were observed for more than 2 years, the mortality reductions became nonsignificant. (Only three randomized controlled trials provided longer term follow-up data, and when results from the large, nonrandomized Recurrent Coronary Prevention Project were added, the longer term follow-up results for mortality became significant.) The authors noted that while the interventions were quite diverse in terms of length, target behavior(s), and specific type of therapy, the results were almost uniformly positive across studies.

In a more recent meta-analysis ${ }^{43}$ examining the effectiveness of psychoeducational interventions (health education and stress management) across 37 studies, there was a $34 \%$ reduction in cardiac mortality, a 29\% reduction in recurrence of myocardial infarctions, and significant positive effects on dietary and exercise habits, weight, smoking, cholesterol, and blood pressure. Data from a recent prospective trial not included in the above review found that patients with coronary artery disease $(\mathrm{n}=94)$ randomized to a stress management intervention evidenced fewer recurrent coronary events at 5-year follow-up compared with those patients receiving usual care. ${ }^{107}$

The evidence for the efficacy of MBTs in hypertension remains somewhat unclear. Although two earlier meta-analyses had questioned the efficacy of relaxation ${ }^{108}$ and cognitive-behavioral interventions ${ }^{44}$ in treating hypertension, a more recent meta-analysis ${ }^{51}$ concluded that MBTs (particularly individualized cognitive-behavioral approaches) were comparable to drug treatments (in terms of raw effect sizes) in reducing both systolic and diastolic blood pressure.

Since this 1994 meta-analysis, several randomized trials have appeared that further suggest the potential efficacy of MBTs in hypertension. A study of older African Americans $(n=127)^{109}$ found that hypertensive patients randomized to a 3 -month trial of transcendental meditation showed significant reductions in systolic and diastolic pressure (10.7 and $6.4 \mathrm{~mm} \mathrm{Hg}$, respectively) compared with those practicing progressive muscle relaxation and an educational control. In a smaller trial $(\mathrm{n}=$ $39),{ }^{110}$ significant reductions in medication requirements were achieved by hypertensive patients randomized to a 6-week multicomponent cognitive-behavioral intervention that included temperature biofeedback, progressive muscle relaxation, and therapy for stress and anger management. Despite these positive findings, however, there are still 
no large-scale trials directly comparing MBTs with either self-monitoring of blood pressure or exercise, diet, and weight-loss interventions.

\section{Insomnia}

Numerous trials as well as several reviews ${ }^{111-114}$ and meta-analyses ${ }^{55,58}$ have examined the efficacy of MBTs for insomnia. ${ }^{113}$ A 1994 meta-analysis of 59 studies $^{55}$ reported that psychological interventions averaging 5 hours produced reliable changes in sleep-onset latency and time awake after sleep. A 1996 NIH consensus panel concluded that MBTs, most notably relaxation and biofeedback, produce significant changes in some aspects of sleep but that it was unclear whether the magnitude of the improvements in sleep onset and total sleep time were clinically significant. ${ }^{68}$ A 1999 systematic review concluded that stimulus control, progressive muscle relaxation, and paradoxical intention met American Psychological Association (APA) criteria for "empirically supported" treatments, whereas three additional approaches-sleep restriction, biofeedback, and multifaceted cognitive-behavioral therapy-met APA criteria for "probably efficacious" treatments. ${ }^{113}$

MBTs can also be helpful in treating late-life insomnia. ${ }^{114} \mathrm{~A}$ recent randomized trial ${ }^{115}$ found that cognitive-behavioral therapy (alone and in combination with pharmacologic therapy) was effective in reducing time awake after sleep onset in elderly patients. Whereas drug therapy alone was also more effective than placebo, only those patients using the behavioral approach maintained treatment gains at follow-up. ${ }^{115}$

Although pharmacological treatments produce somewhat faster sleep improvements in the short term, behavioral approaches in the intermediate term (4-8 weeks) show comparable effects, and in the long-term (6-24 months) behavioral approaches show more favorable outcomes than drug therapies. ${ }^{116}$ The extent to which mind-body and pharmacological therapies can be effectively combined in the treatment of insomnia requires further study. ${ }^{114}$

\section{Surgical Outcomes}

Studies have examined the efficacy of MBTs, such as relaxation, guided imagery, hypnosis, and instructional interventions (eg, providing information about the procedure), before surgery on postsurgical outcomes. ${ }^{117}$ The most recent meta- analysis $^{50}$ found moderate to large effect sizes across several outcomes including pain (effect size $=0.85 ; 95 \%$ CI, $0.17-1.52$ ), medication use (effect size $=0.60 ; 95 \%$ CI, 0.36-0.84), length of stay (effect size $=0.65 ; 95 \%$ CI, 0.24-1.06), and recovery time (effect size $=0.61 ; 95 \%$ CI,-0.95 2.18). These findings are in general agreement with previous meta-analyses ${ }^{42,118-120}$ that found consistent positive treatment effects for MBTs on a variety of postsurgical outcomes. For example, Devine $^{42}$ reports that across 76 studies, length of hospital stay was decreased on average 1.5 days among patients receiving presurgical MBT interventions.

At this point, however, there is no clear evidence regarding which MBTs are most effective, nor is there consensus as to the precise psychophysiological mechanisms (eg, reassurance, patient involvement, sense of control, relaxation-induced immune enhancement) that underlie these observed effects. ${ }^{117}$

\section{Additional Clinical Areas}

There are several other areas that merit further research based either on positive findings from randomized trials or strong theoretical links to psychosocial stress. These include asthma, ${ }^{41,121-124}$ tinnitus, ${ }^{35}$ diabetes, ${ }^{38,125-130}$ chronic obstructive pulmonary disease, ${ }^{40}$ recovery after stroke (muscle re-education using biofeedback), ${ }^{45,54}$ dermatologic conditions, ${ }^{131,132}$ allergies, ${ }^{133}$ irritable bowel syndrome, ${ }^{134-140}$ peptic ulcer, ${ }^{141}$ pregnancy outcomes (where there is strong evidence that emotional support, ie, presence of a doula, has beneficial effects), ${ }^{59,142}$ and human immunodeficiency virus infection. ${ }^{143,144}$

Table 3 summarizes the clinical conditions in which MBTs have shown the strongest evidence of efficacy.

\section{Cost-Effectiveness}

A number of clinical studies ${ }^{18,145-147}$ and narrative reviews ${ }^{42,120,148-150}$ suggest that MBTs can be cost-effective. Most recently, the previously discussed trial conducted by Blumenthal et al, ${ }^{107}$ which showed significant reductions in coronary events for patients randomized to a stress management intervention, found significant cost savings associated with the program (when compared with an exercise program or usual medical care). To date, however, because relatively few MBT trials 
Table 3. Mind-body Therapies: Best Clinical Evidence.

\begin{tabular}{|c|c|c|c|}
\hline Clinical Condition & $\begin{array}{l}\text { Level of } \\
\text { Evidence }\end{array}$ & $\begin{array}{c}\text { Source of Evidence } \\
\text { (Total Number of Patients) }\end{array}$ & Implications for Practice \\
\hline $\begin{array}{l}\text { After myocardial } \\
\text { infarction }\end{array}$ & Strong & $\begin{array}{l}\text { Two positive meta-analyses }{ }^{43,52} \\
(12,879)\end{array}$ & $\begin{array}{l}\text { In addition to the current emphasis on } \\
\text { exercise and nutrition, MBTs (that focus } \\
\text { on the development of self-regulation } \\
\text { skills, such as relaxation and the } \\
\text { management of anger, hostility, and } \\
\text { general stress reactivity) should be included } \\
\text { as part of cardiac rehabilitation }\end{array}$ \\
\hline $\begin{array}{l}\text { Cancer symptoms } \\
\text { (disease and } \\
\text { treatment related) }\end{array}$ & Strong & $\begin{array}{l}\text { Positive results from } 2 \text { meta- } \\
\text { analysis }^{53,71}(\sim 6,166)\end{array}$ & $\begin{array}{l}\text { MBTs (eg, relaxation, hypnosis, supportive } \\
\text { group therapy) should be strongly } \\
\text { considered as adjunctive therapy for cancer } \\
\text { patients, given these therapies' showed } \\
\text { efficacy in improving mood, quality of life, } \\
\text { and coping with both the disease and } \\
\text { treatment-related side effects }\end{array}$ \\
\hline Incontinence disorders & Strong & $\begin{array}{l}\text { Positive results from } 1 \\
\text { meta-analysis }{ }^{98} \text {; AHCPR } \\
\text { guidelines }(240)\end{array}$ & $\begin{array}{l}\text { Biofeedback-assisted muscle retraining in the } \\
\text { treatment of urinary incontinence. Can also } \\
\text { be effective for fecal incontinence, although } \\
\text { additional research is needed }\end{array}$ \\
\hline Surgical outcomes & Strong & $\begin{array}{l}\text { Positive findings from } 2 \text { meta- } \\
\text { analyses }{ }^{42,50}(\sim 6,904)\end{array}$ & $\begin{array}{l}\text { MBTs (eg, relaxation, guided imagery, } \\
\text { hypnosis, instructional interventions) can } \\
\text { be recommended as part of presurgical } \\
\text { preparation, although additional research is } \\
\text { needed to determine the relative efficacy } \\
\text { and cost-effectiveness of these different } \\
\text { approaches }\end{array}$ \\
\hline Insomnia & Strong & $\begin{array}{l}\text { Positive results from meta-analyses } \\
\text { (4,009); NIH Consensus Panel }\end{array}$ & $\begin{array}{l}\text { MBTs (eg, muscle relaxation, cognitive- } \\
\text { behavioral and behavioral therapies, such as } \\
\text { stimulus control) should be considered in } \\
\text { the treatment of insomnia. Additional } \\
\text { research is required to determine how } \\
\text { MBTs might be effectively combined with } \\
\text { pharmacotherapy }\end{array}$ \\
\hline Headache & Strong & $\begin{array}{l}\text { Positive results from } 2 \text { meta- } \\
\text { analyses }^{46,49}(\sim 3,083)\end{array}$ & $\begin{array}{l}\text { The combination of relaxation and thermal } \\
\text { biofeedback can be recommended as } \\
\text { treatment for recurrent migraine, while the } \\
\text { use of relaxation or muscle biofeedback can } \\
\text { be recommended as adjunctive or stand- } \\
\text { alone therapies for tension headaches }\end{array}$ \\
\hline Chronic low back pain & Strong & $\begin{array}{l}\text { Positive findings from } 1 \text { high- } \\
\text { quality meta-analysis }{ }^{62}(1,349)\end{array}$ & $\begin{array}{l}\text { Multi-component MBTs that include some } \\
\text { combination of stress management, coping } \\
\text { skills training, or cognitive restructuring } \\
\text { should be strongly considered as adjunctive } \\
\text { therapies in medical management of } \\
\text { chronic low back pain }\end{array}$ \\
\hline $\begin{array}{l}\text { Osteoarthritis, } \\
\text { rheumatoid arthritis }\end{array}$ & $\begin{array}{l}\text { Moderate- } \\
\text { strong }\end{array}$ & $\begin{array}{l}\text { Positive findings from meta- } \\
\text { analyses }{ }^{36,61} \text { (though effect sizes } \\
\text { generally small and frequently } \\
\text { diminished with time) }(4,337)\end{array}$ & $\begin{array}{l}\text { Multimodal MBTs (that combine education } \\
\text { with such approaches as relaxation, } \\
\text { imagery, biofeedback, and cognitive } \\
\text { behavioral counseling) should be } \\
\text { considered as potentially effective } \\
\text { adjunctive treatments for osteoarthritis and } \\
\text { rheumatoid arthritis }\end{array}$ \\
\hline Hypertension & Moderate & $\begin{array}{l}\text { Positive results from } 1 \text { meta- } \\
\text { analysis }(1,651)^{51} \text { but } \\
\text { contradictory findings in } 2 \\
\text { others }{ }^{44,108}\end{array}$ & $\begin{array}{l}\text { MBTs (particularly multi-component as } \\
\text { opposed to single-component interventions, } \\
\text { such as stand-alone relaxation therapies) } \\
\text { can be potentially useful adjuncts in the } \\
\text { medical management of hypertension }\end{array}$ \\
\hline
\end{tabular}

have included a cost-effectiveness component, additional research is required before definitive conclusions can be drawn regarding the relative costs or cost savings associated with mind-body-psychosocial interventions.

\section{Potential Adverse Effects of Mind-Body Therapies}

Unlike pharmacologic trials, with standardized methods to assess side effects, there appear to be no well-developed or established tools for assessing adverse events associated with MBTs. 
Some persons report experiencing increased anxiety while practicing relaxation techniques. The few small controlled trials that have examined the incidence of such relaxation-induced anxiety have found rates from $17 \%{ }^{151}$ to $31 \%{ }^{152}$ for relaxation to as high as $53.8 \%$ during meditation. ${ }^{152}$ Factors that might be associated with such effects include fear of losing control, general restlessness and fear of inactivity, and fear of letting go. ${ }^{151,153}$ Additional aversive states include unfamiliar feelings and sensations, intrusive thoughts, sense of losing control, floating, dizziness, feelings of vulnerability, sensations of heaviness, and myoclonic jerks. ${ }^{153}$ In a survey of 116 psychologists using relaxation techniques in their practice, the most frequently reported problems encountered by patients were intrusive thoughts (15\%), fear of losing control (9\%), disturbing sensory experiences (4\%), and muscle cramps and spasms (4\%). Respondents reported that they terminated $3.8 \%$ of clients because side effects were seriously interfering with treatment. ${ }^{154}$

It has been suggested that some of these side effects are to be expected and can be used therapeutically. ${ }^{155}$ For example, awareness of physical or psychological tension or stress during the practice of meditation and relaxation can facilitate one's learning to cope more effectively with stressful life situations when they arise.

Studies also suggest that some patients might experience transitory negative effects either during or after hypnosis. ${ }^{156-159}$ These effects include headaches, drowsiness, confusion, dizziness, or nausea, and less frequently anxiety or panic. ${ }^{156}$ Figures range between $5 \%$ to $31 \%$ of those who report experiencing such symptoms. ${ }^{158}$ It has been suggested that the more serious complications are usually the result of the misapplication of hypnotic techniques or simply poor clinical practice (eg, not preparing patients sufficiently). ${ }^{158}$

Given the above findings suggesting that although relatively infrequent, MBTs can give rise to certain negative effects, we concur with Carlson and $\mathrm{Nitz}^{160}$ that it is only prudent to apply such therapies after "careful evaluation of patients and within the context of an appropriate professional relationship."

\section{Directions for Future Research}

In this review we have suggested that a number of MBTs should be considered for inclusion as adjunctive or complementary therapies for several common medical conditions. We have summarized this best clinical evidence in Table 3. We believe, however, a host of clinical and research issues must be better addressed if MBTs are to be more effectively integrated into conventional medical care. These issues include examining the role of MBTs in primary and secondary prevention; comparing the clinical and cost-effectiveness of MBTs against one another to determine more clearly which strategies are most effective under what conditions and for which patients; better clarifying which patients are most likely to respond positively to MBTs and what the key psychosocial, contextual, and dispositional variables might be (ie, emotional distress, readiness to change, desire for control); examining the relative contribution of nonspecific (ie, placebo) factors associated with the effectiveness of MBTs; and continuing to elucidate the mechanisms of action underlying these therapeutic approaches.

\section{Conclusion}

We believe that the cumulative clinical evidence reviewed here lends strong support to the notion that medicine should indeed adopt a biopsychosocial $^{5,7}$ rather than exclusively biologic-genetic model of health.

As summarized in Table 3, based on the positive findings of meta-analyses and randomized controlled trials, there is strong evidence to support the incorporation of an array of mind-body approaches in the treatment of chronic low back pain, coronary artery disease, headache, and insomnia; in preparation for surgical procedures; and in management of the treatment and disease-related symptoms of cancer, arthritis, and urinary incontinence. Although we have noted several areas that future research should address (eg, mechanisms of action of MBTs, the relative contribution of nonspecific factors), given the relatively infrequent and minimal side effects associated with such treatments and the emerging evidence that these approaches can also result in significant cost savings, ${ }^{107}$ we believe that the integration of psychosocial-mind-body approaches, particularly in the clinical areas highlighted above, should be considered a priority for medicine.

\section{References}

1. Rozanski A, Blumenthal JA, Kaplan J. Impact of psychological factors on the pathogenesis of cardio- 
vascular disease and implications for therapy. Circulation 1999;99:2192-217.

2. Kiecolt-Glaser JK. Norman Cousins Memorial Lecture 1998. Stress, personal relationships, and immune function: health implications. Brain Behav Immun 1999;13:61-72.

3. Salovey P, Rothman AJ, Detweiler JB, Steward WT. Emotional states and physical health. Am Psychol 2000;55:110-21.

4. Baum A, Posluszny DM. Health psychology: mapping biobehavioral contributions to health and illness. Annu Rev Psychol 1999;50:137-63.

5. Engel GL. The need for a new medical model: a challenge for biomedicine. Science 1977;196:12936.

6. Shapiro DH, Schwartz CE, Astin JA. Controlling ourselves, controlling our world. Psychology's role in understanding positive and negative consequences of seeking and gaining control. Am Psychol 1996;51:1213-30.

7. Schwartz GE. Testing the biopsychosocial model: the ultimate challenge facing behavioral medicine? J Consult Clin Psychol 1982;50:1040-53.

8. Gulbrandsen P, Hjortdahl P, Fugelli P. General practitioners' knowledge of their patients' psychosocial problems: multipractice questionnaire survey. BMJ 1997;314:1014-8.

9. Hall JA, Stein TS, Roter DL, Rieser N. Inaccuracies in physicians' perceptions of their patients. Med Care 1999;37:1164-8.

10. Levinson W, Gorawara-Bhat R, Lamb J. A study of patient clues and physician responses in primary care and surgical settings. JAMA 2000;284:1021-7.

11. Marvel MK. Involvement with the psychosocial concerns of patients. Observations of practicing family physicians on a university faculty. Arch Fam Med 1993;2:629-33.

12. Roter DL, Stewart M, Putnam SM, Lipkin M Jr, Stiles W, Inui TS. Communication patterns of primary care physicians. JAMA 1997;277:350-6.

13. Tresolini CP, Shugars DA. An integrated health care model in medical education: interviews with faculty and administrators. Acad Med 1994;69: 231-6.

14. Schmidt H. Integrating the teaching of basic sciences, clinical sciences, and biopsychosocial issues. Acad Med 1998;73(9 Suppl):S24-31.

15. Waldstein SR, Neumann SA, Drossman DA, Novack DH. Teaching psychosomatic (biopsychosocial) medicine in United States medical schools: survey findings. Psychosom Med 2001;63:335-43.

16. Bero LA, Grilli R, Grimshaw JM, Harvey E, Oxman $\mathrm{AD}$, Thomson MA. Closing the gap between research and practice: an overview of systematic reviews of interventions to promote the implementation of research findings. The Cochrane Effective Practice and Organization of Care Review Group. BMJ 1998;317:465-8.
17. Eisenberg DM, Davis RB, Ettner SL, et al. Trends in alternative medicine use in the United States, 1990-1997: results of a follow-up national survey. JAMA 1998;280:1569-75.

18. Hellman CJ, Budd M, Borysenko J, McClelland DC, Benson H. The study of the effectiveness of two group behavioral medicine interventions for patients with psychosomatic complaints. Behav Med 1990;16:165-73.

19. Benson H. The relaxation response. New York: Morrow, 1976.

20. Astin JA, Shapiro SL, Schwartz GER. Meditation. In. Novey D, editor. Clinicians' rapid access guide to complementary and alternative medicine. St. Louis: Mosby, 2000.

21. Kabat-Zinn J, Massion AO, Hebert JR, Rosenbaum E. Meditation. In. Holland JC, editor. Textbook on Psycho-oncology. Oxford, England: Oxford University Press, 1998.

22. Goleman DJ, Schwartz GE. Meditation as an intervention in stress reactivity. J Consult Clin Psychol 1976;44:456-66.

23. Shapiro SL, Schwartz GE, Bonner G. The effects of mindfulness-based stress reduction on medical and premedical students. J Behav Med 1998;21: 581-99.

24. Kabat-Zinn J. Mindfulness meditation: What it is, what it isn't, and its role in health care and medicine. In: Haruki Y, Suzuki M, eds. Comparative and psychological study on meditation. Netherlands: Eburon, 1996.

25. Alexander CN, Robinson P, Orme-Johnson DW, Schneider RH. The effects of transcendental meditation compared to other methods of relaxation and meditation in reducing risk factors, morbidity, and mortality. CIANS-ISBM Satellite Conference Symposium: Lifestyle changes in the prevention and treatment of disease (1992, Hannover, Germany). Homeostasis Health Dis 1994;35:243-63.

26. Kabat-Zinn J. An outpatient program in behavioral medicine for chronic pain patients based on the practice of mindfulness meditation: theoretical considerations and preliminary results. Gen Hosp Psychiatry 1982;4:33-47.

27. Spiegel D, Moore R. Imagery and hypnosis in the treatment of cancer patients. Oncology (Huntingt) 1997;11:1179-95.

28. Beck AT. Cognitive therapy and the emotional disorders. New York: International Universities Press, 1979.

29. Ellis A. Reason and emotion in psychotherapy. New York: Lyle Stuart, 1962.

30. Lorig K, Laurin J, Gines GE. Arthritis self-management. A five-year history of a patient education program. Nurs Clin North Am 1984;19:637-45.

31. Astin JA, Harkness E, Ernst E. The efficacy of "distant healing": a systematic review of random- 
ized controlled trials. Ann Intern Med 2000;132: 903-10.

32. Moher D, Cook DJ, Eastwood S, Olkin I, Rennie D, Stroup DF. Improving the quality of reports of meta-analyses of randomized controlled trials: The QUOROM statement. Quality of Reporting of Meta-analyses. Lancet 1999;354:1896-900.

33. Oxman AD, Guyatt GH. Validation of an index of the quality of review articles. J Clin Epidemiol 1991;44:1271-8.

34. Cohen J. Statistical power analysis for the behavioral sciences (2nd ed.). Hillsdale, NJ: Lawrence Erlbaum Associates, 1988.

35. Andersson G, Lyttkens L. A meta-analytic review of psychological treatments for tinnitus. Br J Audiol 1999;33:201-10.

36. Astin JA, Beckner W, Soeken K, Hochberg MC, Berman B. Psychological interventions for rheumatoid arthritis: a meta-analysis of randomized controlled trials. Arthritis Rheum 2002;47:291-302.

37. Berghmans LC, Hendriks HJ, Bo K, et al. Conservative treatment of stress urinary incontinence in women: a systematic review of randomized clinical trials. Br J Urol 1998;82:181-91.

38. Brown SA. Studies of educational interventions and outcomes in diabetic adults: a meta-analysis revisited. Patient Educ Couns 1990;16:189-215.

39. Carroll D, Seers K. Relaxation for the relief of chronic pain: a systematic review. J Adv Nurs 1998; 27:476-87.

40. Devine EC, Pearcy J. Meta-analysis of the effects of psychoeducational care in adults with chronic obstructive pulmonary disease. Patient Educ Couns 1996;29:167-78.

41. Devine EC. Meta-analysis of the effects of psychoeducational care in adults with asthma. Res Nurs Health 1996;19:367-76.

42. Devine EC. Effects of psychoeducational care for adult surgical patients: a meta-analysis of 191 studies. Patient Educ Couns 1992;19:129-42.

43. Dusseldorp E, van Elderen T, Maes S, Meulman J, Kraaij V. A meta-analysis of psychoeduational programs for coronary heart disease patients. Health Psychol 1999;18:506-19.

44. Eisenberg DM, Delbanco TL, Berkey CS, et al. Cognitive behavioral techniques for hypertension: are they effective? Ann Intern Med 1993;118:96472.

45. Glanz M, Klawansky S, Stason W, et al. Biofeedback therapy in poststroke rehabilitation: a metaanalysis of the randomized controlled trials. Arch Phys Med Rehabil 1995;76:508-15.

46. Haddock CK, Rowan AB, Andrasik F, Wilson PG, Talcott GW, Stein RJ. Home-based behavioral treatments for chronic benign headache: a metaanalysis of controlled trials. Cephalalgia 1997;17: $113-8$.

47. Hadhazy VA, Ezzo J, Creamer C, Berman BM.
Mind-body therapies for the treatment of fibromyalgia: A systematic review. J Rheum, in press.

48. Hermann C, Kim M, Blanchard EB. Behavioral and prophylactic pharmacological intervention studies of pediatric migraine: an exploratory meta-analysis. Pain 1995;60:239-55.

49. Holroyd KA, Penzien DB. Pharmacological versus non-pharmacological prophylaxis of recurrent migraine headache: a meta-analytic review of clinical trials. Pain 1990;42:1-13.

50. Johnston M, Vogele C. Benefits of psychological preparation for surgery: a meta-analysis. Ann Behav Med 1993;15:245-56.

51. Linden W, Chambers L. Clinical effectiveness of non-drug treatment for hypertension: a meta-analysis. Ann Behav Med 1994;16:35-45.

52. Linden W, Stossel C, Maurice J. Psychosocial interventions for patients with coronary artery disease: a meta-analysis. Arch Intern Med 1996;156: $745-52$.

53. Meyer TJ, Mark MM. Effects of psychosocial interventions with adult cancer patients: a meta-analysis of randomized experiments. Health Psychol 1995;14:101-8.

54. Moreland JD, Thomson MA, Fuoco AR. Electromyographic biofeedback to improve lower extremity function after stroke: a meta-analysis. Arch Phys Med Rehabil 1998;79:134-40.

55. Morin CM, Culbert JP, Schwartz SM. Nonpharmacological interventions for insomnia: a metaanalysis of treatment efficacy. Am J Psychiatry 1994;151:1172-80.

56. Morley S, Eccleston C, Williams A. Systematic review and meta-analysis of randomized controlled trials of cognitive behaviour therapy and behaviour therapy for chronic pain in adults, excluding headache. Pain 1999;80:1-13.

57. Mullen PD, LaVille EA, Biddle AK, Lorig K. Efficacy of psychoeducational interventions on pain, depression, and disability in people with arthritis: a meta-analysis. J Rheumatol 1987;14(Suppl 15):33-9.

58. Murtagh DR, Greenwod KM. Identifying effective psychological treatments for insomnia: a meta-analysis. J Consult Clin Psychol 1995;63:79-89.

59. Scott KD, Berkowitz G, Klaus M. A comparison of intermittent and continuous support during labor: a meta-analysis. Am J Obstet Gynecol 1999;180: 1054-9.

60. Seers K, Carroll D. Relaxation techniques for acute pain management: a systematic review. J Adv Nurs 1998;27:466-75.

61. Superio-Cabuslay E, Ward MM, Lorig KR. Patient education interventions in osteoarthritis and rheumatoid arthritis: a meta-analytic comparison with nonsteroidal antiinflammatory drug treatment. Arthritis Care Res 1996;9:292-301.

62. van Tulder MW, Ostelo R, Vlaeyen JW, Linton SJ, Morley SJ, Assendelft WJ. Behavioral treatment for 
chronic low back pain: a systematic review within the framework of the Cochrane Back Review Group. Spine 2000;25:2688-99.

63. Jadad AR, Moher M, Browman GP, et al. Systematic reviews and meta-analyses on treatment of asthma: critical evaluation. BMJ 2000;320:537-40.

64. Jadad AR, McQuay HJ. Meta-analyses to evaluate analgesic interventions: a systematic qualitative review of their methodology. J Clin Epidemiol 1996; 49:235-43.

65. Sutton AJ, Duval SJ, Tweedie RL, Abrams KR, Jones DR. Empirical assessment of effect of publication bias on meta-analyses. BMJ 2000;320; 1574-7.

66. Lorig K, Holman H. Arthritis self-management studies: a twelve-year review. Health Educ Q 1993; 20:17-28.

67. Lorig KR, Mazonson PD, Holman HR. Evidence suggesting that health education for self-management in patients with chronic arthritis has sustained health benefits while reducing health care costs. Arthritis Rheum 1993;36:439-46.

68. Integraton of behavioral and relaxation approaches into the treatment of chronic pain and insomnia. NIH Technology Assessment Panel on Integration of Behavioral and Relaxation Approaches into the Treatment of Chronic Pain and Insomnia. JAMA 1996;276:313-8.

69. Holroyd KA, Penzien DB. Psychosocial interventions in the management of recurrent headache disorders. I: Overview and effectiveness. Behav Med 1994;20:53-63.

70. Holroyd KA, O'Donnell FJ, Stensland M, Lipchik GL, Cordingley GE, Carlson BW. Management of chronic tension-type headache with tricyclic antidepressant medication, stress management therapy, and their combination: a randomized controlled trial. JAMA 2001;285:2208-15.

71. Devine EC, Westlake SK. The effects of psychoeducational care provided to adults with cancer: meta-analysis of 116 studies. Oncol Nurs Forum 1995;22:1369-81.

72. Classen C, Butler LD, Koopman C, et al. Supportive-expressive group therapy and distress in patients with metastatic breast cancer: a randomized clinical intervention trial. Arch Gen Psychiatry 2001;58: 494-501.

73. Simonton SS, Sherman AC. Psychological aspects of mind-body medicine: promises and pitfalls from research with cancer patients. Altern Ther Health Med 1998;4:50-64.

74. Cunningham AJ, Tocco EK. A randomized trial of group psychoeducational therapy for cancer patients. Patient Educ Counsel 1989;14:101-14.

75. Cain EN, Kohorn EI, Quinlan DM, Latimer K, Schwartz PE. Psychosocial benefits of a cancer support group. Cancer 1986;57:183-9.

76. Greer S, Moorey S, Baruch JD. Adjuvant psycho- logical therapy for patients with cancer: a prospective randomized trial. BMJ 1992;304:675-80.

77. Burish TG, Jenkins RA. Effectiveness of biofeedback and relaxation training in reducing the side effects of cancer chemotherapy. Health Psychol 1992;11:17-23.

78. Burish TG, Lyles JN. Effectiveness of relaxation training in reducing adverse reactions to cancer chemotherapy. J Behav Med 1981;4:65-78.

79. Morrow GR, Morrell C. Behavioral treatment for the anticipatory nausea and vomiting induced by cancer chemotherapy. N Engl J Med 1982;307: 1476-80.

80. Vasterling J, Jenkins RA, Tope DM, Burish TG. Cognitive distraction and relaxation training for the control of side effects due to cancer chemotherapy. J Behav Med 1993;16:65-80.

81. Spiegel D, Bloom JR. Group therapy and hypnosis reduce metastatic breast carcinoma pain. Psychosom Med 1983;45:333-9.

82. Syrjala KL, Cummings C, Donaldson GW. Hypnosis or cognitive behavioral training for the reduction of pain and nausea during cancer treatment: a controlled clinical trial. Pain 1992;48:137-46.

83. Syrjala KL, Donaldson GW, Davis MW, Kippes ME, Carr JE. Relaxation and imagery and cognitive-behavioral training reduce pain during cancer treatment: a controlled clinical trial. Pain 1995;63: $189-98$.

84. Berglund G, Bolund C, Gustaffson U, Sjoden P. A randomized study of a rehabilitation program for cancer patients: the "starting again" group. Psychooncol 1994;3:109-20.

85. Redd WH, Montgomery GH, DuHamel KN. Behavioral intervention for cancer treatment side effects. J Natl Cancer Inst 2001;93:810-23.

86. Gruber BL, Hersh SP, Hall NR, et al. Immunological responses of breast cancer patients to behavioral interventions. Biofeedback Self Regul 1993; $18: 1-22$.

87. Fawzy FI, Kemeny ME, Fawzy NW, et al. A structured psychiatric intervention for cancer patients. II. Changes over time in immunological measures. Arch Gen Psychiatry 1990;47:729-35.

88. Walker LG, Walker MB, Simpson E. Guided imagery and relaxation therapy can modify host defenses in women receiving treatment for locally advanced breast cancer. Br J Surg 1997;84(Suppl. 1):31.

89. Walker LG, Walker MB, Ogston K, et al. Psychological, clinical and pathological effects of relaxation training and guided imagery during primary chemotherapy. Br J Cancer 1999;80:262-8.

90. Fawzy FI, Fawzy NW, Hyun CS, et al. Malignant melanoma. Effects of an early structured psychiatric intervention, coping, and affective state on recurrence and survival 6 years later. Arch Gen Psychiatry 1993;50:681-9. 
91. Spiegel D, Bloom JR, Kraemer HC, Gottheil E. Effect of psychosocial treatment on survival of patients with metastatic breast cancer. Lancet 1989;2: 888-91.

92. Richardson JL, Shelton DR, Krailo M, Levine AM. The effect of compliance with treatment on survival among patients with hematologic malignancies. J Clin Oncol 1990;8:356-64.

93. Goodwin PJ, Leszcz M, Ennis M, et al. The effect of group psychosocial support on survival in metastatic breast cancer. N Engl J Med 2001;345:171926.

94. Ilnyckyj A, Farber J, Cheang M, et al. A randomized controlled trial of psychotherapeutic intervention in cancer patients. Ann R Coll Physicians Surgeons Canada 1994;27:93-6.

95. Cunningham AJ, Edmonds CV, Jenkins GP, Pollack H, Lockwood GA, Warr D. A randomized controlled trial of the effects of group psychological therapy on survival in women with metastatic breast cancer. Psycho-oncology 1998;7:508-17.

96. Linn MW, Linn BS, Harris R. Effects of counseling for late stage cancer. Cancer 1982;49:1048-55.

97. Fantl JA, Newman DK, Colling J, et al. Urinary incontinence in adults: acute and chronic management. Rockville, Md: US Department of Health and Human Services, Public Health Service, Agency for Health Care Policy and Research, 1996. AHCPR publication 96-0682.

98. Weatherall M. Biofeedback or pelvic floor muscle exercises for female genuine stress incontinence: a meta-analysis of trials identified in a systematic review. BJU Int 1999;83:1015-16.

99. Hirsch A, Weirauch G, Steimer B, et al. Treatment of female urinary incontinence with EMG-controlled biofeedback home training. Int Urogynecol J Pelvic Floor Dysfunct 1999;10:7-10.

100. Burgio KL, Locher JL, Goode PS, et al. Behavioral vs drug treatment for urge urinary incontinence in older women: a randomized controlled trial. JAMA 1998;280:1995-2000.

101. Glavind K, Laursen B, Jaquet A. Efficacy of biofeedback in the treatment of urinary stress incontinence. Int Urogynecol J Pelvic Floor Dysfunct 1998;9:151-3.

102. Glia A, Gylin M, Akerlund JE, Lindfors U, Lindberg G. Biofeedback training in patients with fecal incontinence. Dis Colon Rectum 1998;41:359-64.

103. Norton C, Kamm MA. Outcome of biofeedback for faecal incontinence. Br J Surg 1999;86:1159-63.

104. Fynes MM, Marshall K, Cassidy M, et al. A prospective, randomized study comparing the effect of augmented biofeedback with sensory biofeedback alone on fecal incontinence after obstetric trauma. Dis Colon Rectum 1999;42:753-61.

105. Chiotakakou-Faliakou E, Kamm MA, Roy AJ, Storrie JB, Turner IC. Biofeedback provides long-term benefit for patients with intractable, slow and normal transit constipation. Gut 1998;42:517-21.

106. Ko CY, Tong J, Lehman RE, Shelton AA, Schrock TR, Welton ML. Biofeedback is effective therapy for fecal incontinence and constipation. Arch Surg 1997;132:829-4.

107. Blumenthal JA, Babyak M, Wei J, et al. Usefulness of psychosocial treatment of mental stress-induced myocardial ischemia in men. Am J Cardiol 2002;89: 164-8.

108. Jacob RG, Chesney MA, Williams DM, Ding Y, Shapiro AP. Relaxation therapy for hypertension: design effects and treatment effects. Ann Behav Med 1991;13:5-17.

109. Schneider RH, Staggers F, Alexander CN, et al. A randomized controlled trial of stress reduction for hypertension in older African Americans. Hypertension 1995;26:820-7.

110. Shapiro D, Hui KK, Oakley ME, Pasic J, Jamner LD. Reduction in drug requirements for hypertension by means of a cognitive-behavioral intervention. Am J Hypertens 1997;10:9-17.

111. Lichstein KL, Riedel BW. Behavioral assessment and treatment of insomnia: a review with an emphasis on clinical application. Behav Ther 1994;25: 659-88.

112. Lundh LG. Cognitive-behavioural analysis and treatment of insomnia. Scand J Behav Ther 1998; 27:10-29.

113. Morin CM, Hauri PJ, Espie CA, Spielman AJ, Buysse DJ, Bootzin RR. Nonpharmacologic treatment of chronic insomnia. An American Academy of Sleep Medicine review. Sleep 1999;22:1134-56.

114. Morin CM, Mimeault V, Gagne A. Nonpharmacological treatment of late-life insomnia. J Psychosom Res 1999;46:103-16.

115. Morin CM, Colecchi C, Stone J, Sood R, Brink D. Behavioral and pharmacological therapies for latelife insomnia: a randomized controlled trial. JAMA 1999;281:991-9.

116. Morin CM, Culbert JP, Schwartz SM. Nonpharmacological interventions for insomnia: a metaanalysis of treatment efficacy. Am J Psychiatry 1994; 151:1172-80.

117. Dreher H. Mind-body interventions for surgery: Evidence and exigency. Adv Mind-Body Med 1998; 14:207-22.

118. Mumford E, Schlesinger HJ, Glass GV. The effect of psychological interventions on recovery from surgery and heart attacks: an analysis of the literature. Am J Public Health 1982;72:141-51.

119. Hathaway D. Effect of preoperative instruction on postoperative outcomes: a meta-analysis. Nurs Res 1986;35:269-75.

120. Devine EC, Cook TD. Clinical and cost-saving effects of psychoeducational interventions with surgical patients: a meta-analysis. Res Nurs Health 1986;9:89-105. 
121. Lehrer PM. Emotionally triggered asthma: a review of research literature and some hypotheses for selfregulation therapies. Appl Psychophysiol Biofeedback 1998;23:13-41.

122. McQuaid EL, Nassau JH. Empirically supported treatments of disease-related symptoms in pediatric psychology: asthma, diabetes, and cancer. J Pediatr Psychol 1999;24:305-28.

123. Castes M, Hagel I, Palenque M, Canelones P, Corao A, Lynch NR. Immunological changes associated with clinical improvement of asthmatic children subjected to psychosocial intervention. Brain Behav Immun 1999;13:1-13.

124. Smyth JM, Stone AA, Hurewitz A, Kaell A. Effects of writing about stressful experiences on symptom reduction in patients with asthma or rheumatoid arthritis: a randomized trial. JAMA 1999;281: 1304-9.

125. Surwit RS, van Tilburg MA, Zucker N, et al. Stress management improves long-term glycemic control in type 2 diabetes. Diabetes Care 2002;25:30-4.

126. McGrady A, Graham G, Bailey B. Biofeedbackassisted relaxation in insulin-dependent diabetes: A replication and extension study. Ann Behav Med 1996;18:185-9.

127. Fosbury JA, Bosley CM, Ryle A, Sonksen PH, Judd SL. A trial of cognitive analytic therapy in poorly controlled type I patients. Diabetes Care 1997;20: 959-64.

128. Jablon SL, Naliboff BD, Gilmore SL, Rosenthal MJ. Effects of relaxation training on glucose tolerance and diabetic control in type II diabetes. Appl Psychophysiol Biofeedback 1997;22:155-69.

129. Aikens JE, Kiolbasa TA, Sobel R. Psychological predictors of glycemic change with relaxation training in non-insulin-dependent diabetes mellitus. Psychother Psychosom 1997;66:302-6.

130. Henry JL, Wilson PH, Bruce DG, Chisholm DJ, Rawling PJ. Cognitive-behavioural stress management for patients with non-insulin dependent diabetes mellitus. Psychol Health Med 1997;2:109-18.

131. Bilkis MR, Mark KA. Mind-body medicine. Practical applications in dermatology. Arch Dermatol 1998;134:1437-41.

132. Kabat-Zinn J, Wheeler E, Light T, et al. Influence of a mindfulness meditation-based stress reduction intervention on rates of skin clearing in patients with moderate to severe psoriasis undergoing phototherapy (UVB) and photochemotherapy (PUVA). Psychosom Med 1998;60:625-32.

133. Watkins AD. The role of alternative therapies in the treatment of allergic disease. Clin Exp Allergy 1994;24:813-25.

134. Blanchard EB, Malamood HS. Psychological treatment of irritable bowel syndrome. Prof Psychol Res Pract 1996;27:241-4.

135. Schwarz SP, Taylor AE, Scharff L, Blanchard EB. Behaviorally treated irritable bowel syndrome pa- tients: a four-year follow-up. Behav Res Ther 1990; 28:331-5.

136. Blanchard EB, Greene B, Scharff L, Schwarz-McMorris SP. Relaxation training as a treatment for irritable bowel syndrome. Biofeedback Self Regul 1993;18:125-32.

137. Galovski TE, Blanchard EB. The treatment of irritable bowel syndrome with hypnotherapy. Appl Psychophysiol Biofeedback 1998;23:219-32.

138. Payne A, Blanchard EB. A controlled comparison of cognitive therapy and self-help support groups in the treatment of irritable bowel syndrome. J Consul Clin Psychol 1995;63:779-86.

139. Greene B, Blanchard EB. Cognitive therapy for irritable bowel syndrome. J Consul Clin Psychol 1994;62:576-82.

140. Vollmer A, Blanchard EB. Controlled comparison of individual versus group cognitive therapy for irritable bowel syndrome. Behav Ther 1998;29:19_ 33.

141. Levenstein S, Ackerman S, Kiecolt-Glaser JK, Dubois A. Stress and peptic ulcer disease. JAMA 1999;281:10-1.

142. Zhang J, Bernasko JW, Leybovich E, Fahs M, Hatch MC. Continuous labor support from labor attendant for primiparous women: a meta-analysis. Obstet Gynecol 1996;88(4 Pt 2):739-44.

143. Cruess DG, Antoni MH, Kumar M, et al. Cognitive-behavioral stress management buffers decreases in dehydroepiandrosterone sulfate (DHEA-S) and increases in the cortisol/DHEA-S ratio and reduces mood disturbance and perceived stress among HIV-seropositive men. Psychoneuroendocrinology 1999;24:537-49.

144. Robinson FP, Mathews HL, Witek-Janusek L. Stress and HIV disease progression: psychoneuroimmunological framework. J Assoc Nurses AIDS Care 1999; 10:21-31.

145. Kruger JM, Helmick CG, Callahan LF, Haddix AC. Cost-effectiveness of the Arthritis Self-Help Course. Arch Intern Med 1998;158:1245-9.

146. Kennell J, Klaus M, McGrath S, Robertson S, Hinkley C. Continuous emotional support during labor in a US hospital: a randomized controlled trial. JAMA 1991;265:2197-201.

147. Caudill M, Schnable R, Zuttermeister P, Benson H, Friedman R. Decreased clinic use by chronic pain patients: response to behavioral medicine interventions. Clin J Pain 1991;7:305-10.

148. Sobel DS. Rethinking medicine: improving health outcomes with cost-effective psychosocial interventions. Psychosom Med 1995;57:234-44.

149. Friedman R, Sobel D, Myers P, Caudill M, Benson H. Behavioral medicine, clinical health psychology, and cost offset. Health Psychol 1995;14:509-18.

150. Schneider CJ. Cost effectiveness of biofeedback and behavioral medicine treatments. A review of the literature. Biofeedback Self Regul 1987;12:71-92. 
151. Braith JA, McCullough JP, Bush JP. Relaxationinduced anxiety in a subclinical sample of chronically anxious subjects. J Behav Ther Exp Psychiatry 1988;19:193-8.

152. Heide FJ, Borkovec TD. Relaxation-induced anxiety: paradoxical anxiety enhancement due to relaxation training. J Consult Clin Psychol 1983;51:17182.

153. Lazarus AA, Mayne TJ. Relaxation: some limitations, side effects, and proposed solutions. Psychotherapy 1990;27:261-6.

154. Edinger JD, Jacobsen R. Incidence and significance of relaxation treatment side effects. Behav Ther 1982;5:137-8.

155. Woolfolk RL, Lehrer PM, editors. Principles and practice of stress management. 2nd ed. New York: Guilford Press, 1993.

156. MacHovec F. Hypnosis complications, risk factors, and prevention. Am J Clin Hypn 1988;31:40-9.

157. Barber J. When hypnosis causes trouble. Int J Clin Exp Hypn 1998;46:157-70.

158. Lynn SJ, Martin DJ, Frauman DC. Does hypnosis pose special risks for negative effects? A master class commentary. Int J Clin Exp Hypn 1996;44:7-19.

159. Page RA, Handley GW. In search of predictors of hypnotic sequelae. Am J Clin Hypn 1996;39:93-6.

160. Carlson CR, Nitz AJ. Negative side effects of selfregulation training: relaxation and the role of the professional in service delivery. Biofeedback Self Regul 1991;16:191-7. 